\title{
Study on Correlation between Agricultural Production and Agricultural \\ Economy of Xinjiang
}

\author{
Mengtao Zhang ${ }^{1}$, Chuanhui Zhang ${ }^{1}$ \\ ${ }^{1}$ Tarim University, Alar, Xinjiang, 843300
}

KEYWORDS: Xinjiang; Agricultural Economy; Agricultural Production; Association

\begin{abstract}
Agriculture is the main industry, form part of the main income of rural residents in Xinjiang and Xinjiang economy. Q. I mainly from the impact of the Agricultural Industry on Xinjiang agricultural economy, analyzes the current relevance of agricultural production in Xinjiang and Xinjiang agricultural economy, come to land, capital and labor inputs to agriculture in Xinjiang's economic growth has a positive effect . I believe that through increased investment in agriculture in Xinjiang capital, rational development and utilization of Xinjiang vast land resources and increase agricultural labor supply, increase investment in agricultural science and technology in Xinjiang, a sound agricultural development policy system to be able to effectively help the economic growth of Xinjiang Agricultural . I also hope that through this research to the future development of Xinjiang Agricultural provide reference and help.
\end{abstract}

\section{Introduction}

Agricultural economy is the core of economic development in Xinjiang, Xinjiang agricultural economy while also one of the important factors of economic development and social stability in Xinjiang rapid progress. As we all know, promote agricultural growth factors derived from agricultural production factors of land, capital, labor and policy system and so on. Occupying a land area of Xinjiang in recent sixth, so healthy and stable development of Xinjiang's agricultural economy to improve the overall level of economic Xinjiang, solve the "three rural" issue has a very important role. Xinjiang, northwest China, as a major agricultural autonomous region, its rich land resources, environmental conditions for economic growth provided favorable conditions and guarantees. Although Xinjiang has a variety of conditions necessary for the development of agriculture, arable land in Xinjiang is also increasing, but its agricultural economy has been lagging behind the national average for other provinces, Xinjiang rural incomes are relatively low, it still boils down to capital , technology and labor was scarce and other factors related. Thus, the author of this article from the current development of agriculture in Xinjiang start on the relevance of agricultural production and the agricultural economy in Xinjiang were analyzed proposed several measures to promote agricultural economic development in Xinjiang.

\section{The Status of Xinjiang Agricultural Development}

Current Agricultural combine their own actual situation, put forward bases in Xinjiang Agricultural Development-related policies, there are major developments in the base construction of Xinjiang cotton industry, animal husbandry bases in Xinjiang characteristics of forest base construction and 
characteristics of the country and so on. However, overall, this type of infrastructure in Xinjiang is still not perfect, and even some projects may be unreasonable.

From the most recent census data, we can understand that the rural population in Xinjiang have nearly $50 \%$ of farmers only primary school education, low level of education generally the case shows that the presence of the agricultural labor force in Xinjiang. This situation is too traditional agricultural production, new agricultural production techniques are not promptly used for agricultural production in Xinjiang, which will inevitably lead to the agricultural economy in Xinjiang lags behind other regions.

All along, all of Xinjiang province animal husbandry and a big heavy, but because in recent years leading to overgrazing of grassland degradation in Xinjiang is more serious, in this case, the development of animal husbandry has been greatly restricted, in addition to animal husbandry has always been more traditional mode of production, backward mode of production, making the development of animal husbandry in Xinjiang affected the healthy development of the whole agricultural economy.

A perfect sound agricultural system is a necessary guarantee for the promotion of agricultural development and progress of Xinjiang. Xinjiang is the province of agricultural development, but due to the vast Xinjiang region, plus I located across the border provinces, adjacent to Central Asia and many other countries, due to national border plants, the high incidence of high incidence of epidemic animal agriculture in Xinjiang will have a great impact. Affected by these cases, the measures in Xinjiang Agricultural Development System possible implementation is not in place and implement unrealistic.

Due to low Xinjiang people, the presence of regional policy plan for each very different, each area exists on the resources, these external factors are such that there exists between the Xinjiang regional development imbalance, such as three southern states the development of agriculture will seriously lagging behind in the northern and eastern Xinjiang's agricultural development. Natural agricultural economy at large in the Xinjiang Autonomous Region also presented a great imbalance.

Compared with other provinces, Xinjiang Agriculture Agricultural industrialization process is relatively slow, deep processing of agricultural characteristics exist unbalanced regional development, the degree of processing is not high. The province's industrial management of agriculture enterprises is less, most in the initial stage of processing, so that the degree of agricultural products processing and conversion is not high. Thus, the industrial development of such slow agricultural products not fully utilized, a serious impediment to the rapid development of Xinjiang's agricultural economy.

\section{Agricultural Production and Agro-Economic Relevance}

In fact, agricultural production and business need for the cost of capital investment. No capital investment is just empty talk, without mentioning the introduction of advanced production technology, to talk about how to increase labor inputs. Studies have shown that a reasonable capital investment, not only allows mechanization of agricultural production, labor will be more reasonable to use other agricultural production process, but also to attract other companies to join the Xinjiang agricultural production and processing sectors, the deposit conversion into agricultural products. In addition, the production process, the introduction of new production processes as well as technical support in the agricultural fertilizer pesticide and so need to have funds for the job. Therefore, a reasonable capital investment is very important, cannot make bricks without straw, only to protect the funds, agricultural economic development to become possible. 
In order to ensure funding for the effective investment, science and technology to use and customize to participate in the labor force, the relevant departments of the policy system is indispensable. Only policy system in place to ensure that rural residents in Xinjiang raise awareness of agricultural production, the province and other provinces to attract more businesses into the development of agricultural industrialization in Xinjiang. Meanwhile, the policy system as a whole can have a whole Xinjiang careful planning, there is a single area of realistic development strategy, this will be the development of Xinjiang Agricultural regulation, balanced development of the agricultural economy in Xinjiang plays a role in safeguarding.

Because of the vast land, Xinjiang is not always a shortage of agricultural land and other productive resources is a major agricultural province, but is affected by many factors, climate, rarely Xinjiang rational use of land resources together. Now, with the improvement of agricultural production conditions in Xinjiang, a lot of resources to be able to make the best use, for example, agricultural production in many regions of Xinjiang us improve agricultural production conditions, so that the crops from the traditional one crop a year, now becomes two crops a year, or even increase production capacity still, which makes efficient use of land resources has been greatly improved, which for speeding up agricultural economic development in Xinjiang has a very important role. Plus there are a lot of land in Xinjiang did not yet developed, Xinjiang land resources developed for the diversity of agricultural products, diversified agricultural economy in Xinjiang has great significance.

China's agricultural production has been mainly in the family as a unit small-scale agricultural production, in this case, the one benefit of farmers in agricultural production is very tiny, and secondly, such a production model for the sustainable development of the agricultural economy in Xinjiang to They say it is negative. However, by improving the conditions of agricultural production, agricultural machinery and the introduction of advanced science and technology, we can be the traditional family unit of such small-scale agricultural production to optimize and reform, while the use of advanced large-scale agricultural production equipment can be achieved in Xinjiang scale development of agricultural production activities, greatly reducing the process of agricultural production unit costs. Thus, advanced science and technology to speed up the rate of production of agricultural production, reduce the loss of production of products, improves production yields has a great help. Agricultural science and technology to economic growth plays an important catalytic role.

\section{Promote Agricultural Economic Development in Xinjiang Suggestions}

Speaking in front of our capital invested in agricultural production is a prerequisite for the promotion of agricultural economic growth, we can imagine the economic growth of Xinjiang Agricultural decide within a reasonable agricultural funds invested in large part. Since most Xinjiang region prevailing weaker economic situation, each region can put less money into agricultural production, coupled with the economic strength of farmers own very limited. Therefore, the relevant government departments should be used as the main investment in agriculture, constant introduction of multi-level, multi-channel investment way, full use of corporate capital and private capital, so that more capital flows to social development in Xinjiang's agricultural production. At the same time, increase investment funds for high-standard farmland and water conservancy facilities construction, for agricultural development to provide the necessary infrastructure to ensure rapid and steady growth of agricultural economy in Xinjiang.

Agricultural production is inseparable from the land, Agricultural economic growth is inseparable from the natural land use. In order to better promote hair growth in the agricultural 
economy in Xinjiang, we not only develop and increase the use of the land area, but also to maximize the use of existing number of land resources. Land to invest more, but if the use of land resources is low, resulting in waste of land resources, thereby enabling the supply of land resources become more strained. On the other hand, improve the utilization of land resources, the use of advanced production technology, in the original land resources, crops are ripe crops a year, then the two crops a year, or the introduction of other feed crops can co-planted crops. Such rational development and intensive use of land resources and improve yields, the introduction of other crops, improve land utilization.

While the current mechanization of agricultural production has increased a great convenience for agricultural production, but the development of the current situation cannot do agricultural production. Therefore, in order to promote faster economic growth in agriculture, increase agricultural production in the Xinjiang labor inputs have to be necessary. First, we should encourage enterprises from other provinces and the self-employed to Xinjiang land reclamation, development of Xinjiang Agricultural land contract; secondly, to develop a number of financial, tax and other preferential policies to attract other businesses to Xinjiang engaged in agricultural production. We must recognize that the promotion of the development of agriculture is not thought to increase the labor force, but to the labor force in agricultural production to meet the necessary human resources, adequate and reasonable labor and machinery technology will want to combine in order to effectively promote agricultural development in Xinjiang and growth.

Agricultural production agricultural science and technology to economic growth catalyst, through the introduction of advanced agricultural science and technology, can improve production efficiency of land, increase product yield, greatly improve the utilization of land. Therefore, the relevant government departments should continue to introduce new technology and train a number of high-level, strong operational capacity of agricultural production and technical staff, and to get them to farmers for agricultural production technical training and guidance to improve the overall level of agricultural production. The only way to speed up the rate of agricultural production, increase productivity unit product utilization per unit area is prompting Agricultural rapid economic growth.

Establish a sound system of policies to promote agricultural development in Xinjiang, Xinjiang to increase efforts to support agricultural production, with the help of the system under the policy, so that the province of rural residents realize large prospects for agricultural development in Xinjiang, to encourage businesses to invest in the processing of agricultural products, which actively for agricultural production the introduction of advanced science and technology, the development of agricultural production resources have significance for sustainable development, improve sales channels Xinjiang agricultural products. With the help of the system under the policy to accelerate the development of agricultural production, promoting agricultural economy in Xinjiang is stable, healthy and rapid growth.

\section{Conclusion}

Xinjiang, located in China's northwest border, due to the harsh natural climatic conditions over the years, it has been various factors such as natural disasters affect national borders, coupled with relatively slow agricultural development in Xinjiang, Xinjiang's agricultural economy has been lagging behind the overall level of China's agricultural economy. So therefore in order to better accelerate the development of agriculture in Xinjiang, Xinjiang to promote the rapid and stable development of the agricultural economy, seize the key factors in agricultural production funds, resources, labor and policy system, etc. it is very important. Meanwhile, the only practical Xinjiang 
agricultural production for each of the key factors, make relevant policies to ensure the healthy and stable development of the rapid development of Xinjiang's agriculture, economy to growth. Future agricultural production in Xinjiang is bound to develop air leap.

\section{Acknowledgements}

Fund Project: the National Social Science Fund Project (13xk8008);

Ministry of Education, "New Century Talents Support Program" (NCET-13-0925);

Xinjiang Production and Construction Corps Excellence Project

Xinjiang Production and Construction Corps Soft Science Projects (03704196)

\section{References}

[1] Zhang Ruili, Huang Mingfeng. adjustment of agricultural structure impact on farmers' income Effect - A Case Study [J]. Economic Research Guide, 2010 (11).

[2] Luo Fang, Huang Yan. Xinjiang agricultural economic growth and agricultural production factors correlation analysis [J]. Journal of Shihezi University (Philosophy and Social Sciences), 2013 (06).

[3] Yang Zhongna, Tang Jijun, Yu Xiaoling. Influence and Countermeasures in Xinjiang cotton industry to the national economy [J]. Research of Agricultural Modernization, 2013 (05).

[4] Chao Weipeng, Sun Jian. 1990--2011 agricultural production factor Xinjiang Agricultural Investment and the Economic Growth [J]. Guizhou Agricultural Sciences, 2013 (11).

[5] Li Shipeng, Luo Shuai. Agricultural Industrial Structure Adjustment on Agricultural Economic Growth [J]. Journal of Anhui Agricultural Sciences, 2012 (08).

[6] Zhang Jianping. multivariate statistical agricultural production conditions on agricultural economic development impact analysis [J]. Agriculture and Technology, 2007 (01). 